\title{
EFFECTS OF COVID-19 ON EDUCATION AND FUNCTIONING OF HEALTHCARE FACULTIES IN DENIZLI, TURKEY: A SURVEY STUDY
}

\author{
Özge Gizem Cabadağ, Nilgün Akgül, Başak Yazkan \\ Department of Restorative Dentistry, Faculty of Dentistry, Pamukkale University, Turkey
}

\begin{abstract}
INTRODUCTION: The novel coronavirus disease, COVID-19, which evolved in Wuhan city of China, has become an important public health emergency that paralyzed life and negatively affected the entire world.

ОвJеCтIVEs: The aim of the study was to evaluate a possible effect of coronavirus pandemic on healthcare from the perspective of academicians.

MATERIAL AND METHODS: A questionnaire consisting of education and functioning of medical-related faculties in the process of COVID-19 was completed by academicians in medical sciences. Data obtained from surveys were presented in pie/column charts and percentages.

RESULTS: A total of 103 academicians contributed to the survey. Most of the participants were concerned about themselves and their families. Due to the COVID-19 pandemic, academicians indicated a permanent change in healthcare system. In addition, they expressed worries about theoretical part of distance education and the effects of distance education on clinical practices.

ConcLusions: According to obtained results, academicians in medical sciences reported significant changes occurring not only in providing healthcare services but also in educational aspect, which is a subject of concern. In this period, in which restrictive and compelling effects are felt in the medical sector as in many other industries, there are still uncertainties regarding the future, and it can be seen that the "normal life" will never be the same as before.
\end{abstract}

KEY wORDs: survey, education, healthcare, COVID-19, pandemic.

J Stoma 2021; 74, 1: 38-45

DOI: https://doi.org/10.5114/jos.2021.104697

\section{INTRODUCTION}

In late December of 2019, in Wuhan city of China, a new type of coronavirus (2019-nCoV) has been identified [1]; a virus, that has never been detected in a human and characterized by pneumonia. Because of its taxonomic similarities with a virus, causing severe acute respiratory syndrome (SARS), it was named as "SARS-CoV-2" by the International Committee on Taxonomy of Vi- ruses - Coronavirus Study Group (ICTV-CSG) [2, 3]. The World Health Organization (WHO) announced COVID-19 as an "international public health emergency" due to the fact that it spread over a very large area in a very short period. Subsequently, after intercontinental spread, it was declared as a pandemic on March $11^{\text {th }}$, 2020 [4].

Although clinical symptoms of SARS-CoV-2 infected patients differ, they generally complain of fever (98\%), dry

\section{JOURNAL OF} STOMATOLOGY 
cough (76\%), weakness (70\%), shortness of breath (55\%), fatigue (44\%), and atypical symptoms, such as muscle pain, sore throat, headache, hemoptysis, and diarrhea $[5,6]$. Findings, which most frequently were seen in computed tomography (CT) images of these patients included bilateral pneumonia, ground-glass appearance, and bilateral irregular areas in the lungs $[7,8]$. Current observations showed that any person from any age-group may become infected with COVID-19, but geriatric patients, those having cardiovascular and cerebrovascular diseases, diabetes, and hypertension are under significantly higher risk. It was reported that prognosis for such patients were worse than for those from other groups of patients $[6,8,9]$. This disease can be accurately diagnosed by using a detailed anamnesis with identified risk factors, detection of afore-mentioned clinical symptoms, CT findings, and laboratory tests, such as reverse transcriptase-polymerase chain reaction (RT-PCR) $[5,10]$.

The possible ways of the COVID-19 dissemination are direct transmission through coughing, sneezing, and inhalation of droplets as well as through contact with oral, nasal, and ocular mucosa [11]. Moreover, it was also reported that SARS-CoV-2 might be transmitted through aerosols originating from medical procedures [12]. Even though the main source of infection are the symptomatic COVID-19 patients, the asymptomatic patients and/or those in the incubation period also play important role in the spread of the disease $[13,14]$. The accepted incubation period for the infection is known to be 1-14 days as well as the follow-up and quarantine period for suspicious/infected individuals was established to be 14 days $[5,13]$. Since no precise method can be offered to control and treat the disease, the recommended golden standard is to control the origin of infection. For this purpose, in order to minimize the transmission risk, early diagnosis, isolation, and required healthcare support for infected individuals as well as strict obedience of the measures taken are all very important [8].

Occupations that are related with medical sciences are classified as very-high-risk category, because of high potential of coronavirus exposure [15]. In Turkey during the pandemic, as in all countries struggling with COVID-19 disease, it was decided to postpone nonemergency medical elective surgical and dental care procedures for a certain period. Then, similar to public/ private institutions offering healthcare services, also the universities' faculties related to medical sciences started to return to routine clinical procedures due to both financial difficulties and an increase in treatment necessities of patients.

\section{OBJECTIVES}

The COVID-19 pandemic has been causing problems in many areas and the healthcare sector is among the leading ones. Healthcare professionals, such as doctors, dentists, nurses, and physiotherapists, are at the forefront of fighting the disease. The present survey assessed views of occupations associated with medical sciences on the COVID-19 pandemic.

At the moment, it is unknown how long this present situation will last, and a third wave is very much possible. In this difficult period, healthcare personnel had to alter their behaviors and attitudes, make arrangements in their clinical practice environments, and take additional measures in order to prevent the cross-infection risk between healthcare personnel and patients. Also academicians had to continue their educational activities through a distance education system. The purpose of this survey was to determine the opinions about the pandemic while collecting data from academic healthcare personnel.

\section{MATERIAL AND METHODS}

This study was approved by the Ministry of Health, Republic of Turkey (No. 2020-09-01T21_28_04). Ethical approval was obtained from the ethics committee of Pamukkale University (No. 60116787-020/58764).

In the present survey, the academicians working at Pamukkale University's Faculty of Medicine, Faculty of Dentistry, Faculty of Health Sciences - Department of Nursing, and Physiotherapy and Rehabilitation were involved; the volunteering individuals were requested to answer the survey questions. None of identifying personal data (name, surname, ID number) of the participants were recorded. Participation in the survey was voluntary and the process was in accordance with the Helsinki Declaration. The participants were given an informative text about the study.

The survey used in the present study consisted of demographic information and items related to COVID-19. First, by using keywords, such as "COVID-19", "coronavirus", "healthcare sector", and "survey", a search was made in English and Turkish languages. Then, an 18-item survey was derived using relevant sources. The survey was prepared in a survey portal (https://docs.google. com/forms/) and the URL address was e-mailed to academicians asking them to respond. In the data collection step, 103 survey forms were taken into analysis and the data obtained were presented in pie/column charts and percentages.

\section{RESULTS}

In the present study, it can be seen that $51.5 \%$ of participants were female and $48.5 \%$ were male. From an aspect of academic title, the largest portion (81.6\%) consisted of research assistants, followed by Dr. Lecturer, Assoc. Prof. Dr., and Prof. Dr. The mean age of 103 participants was found to be 31.5 years, and $28.4 \%$ of par- 


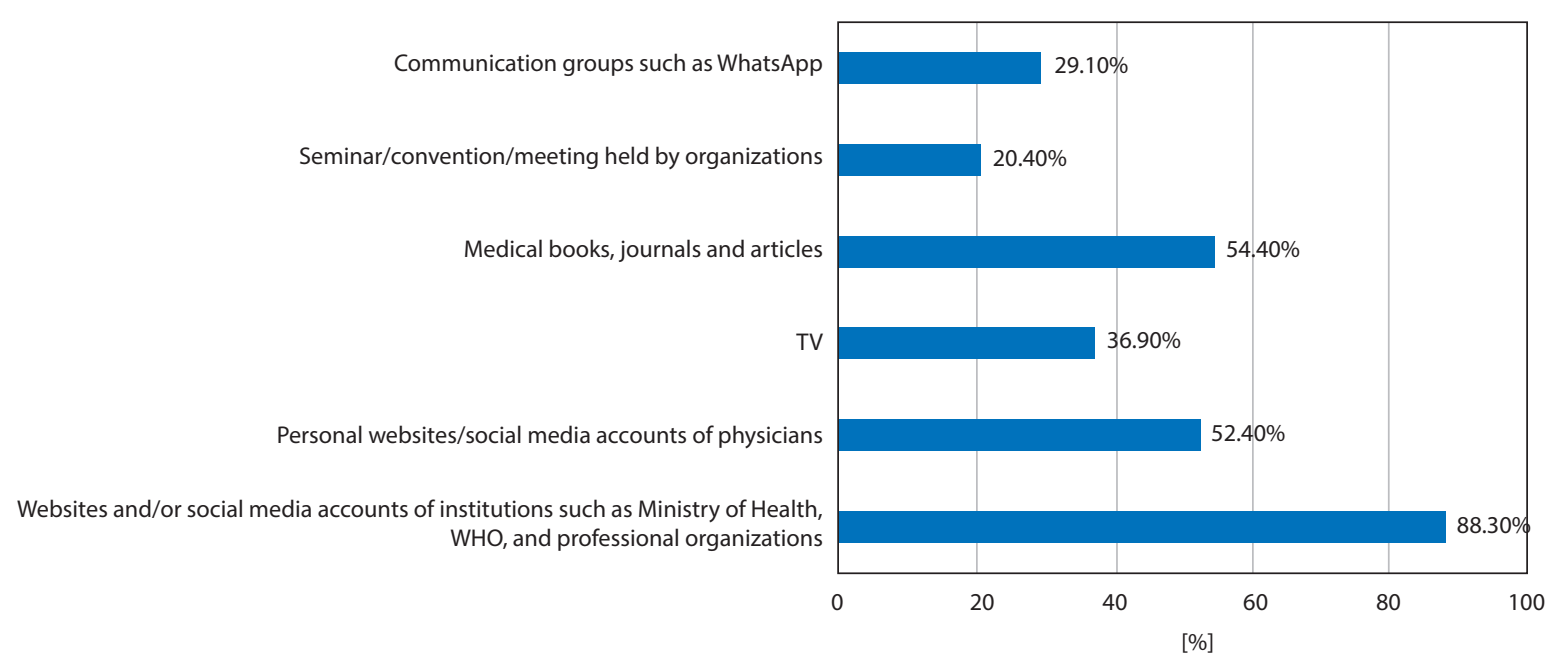

FIGURE 1. Academicians' sources of information about COVID-19

A

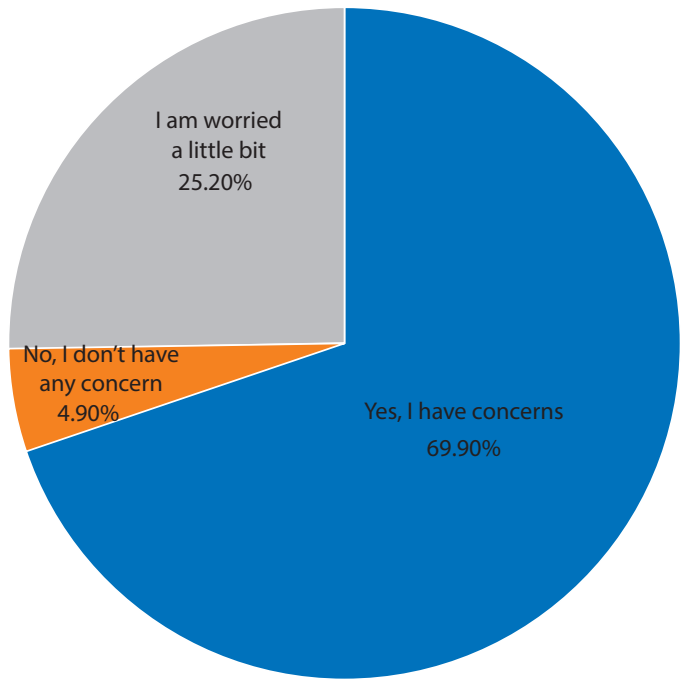

FIGURE 2. Academicians' concerns about A) their health,

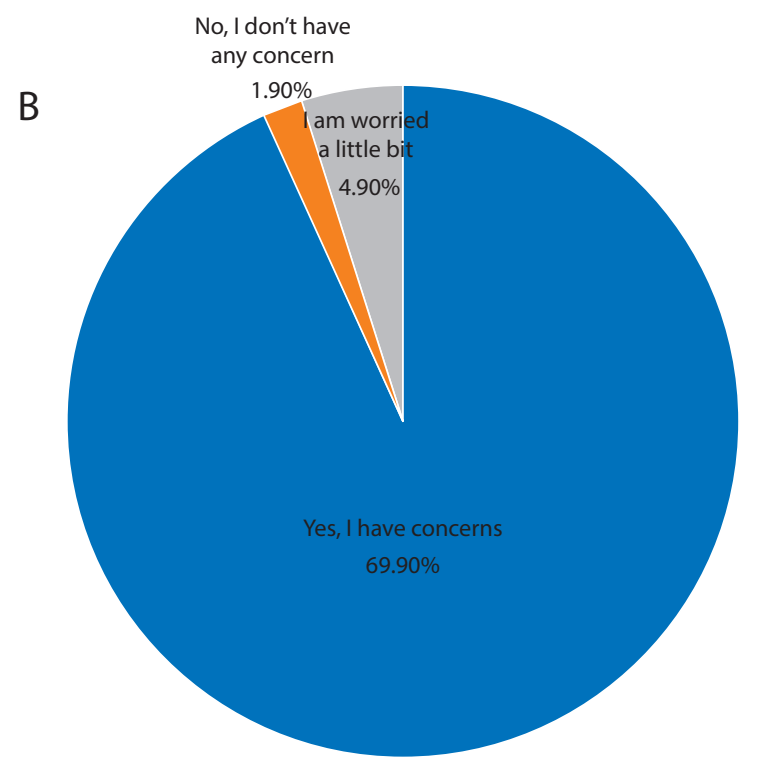

B) transmitting COVID-19 to their relatives

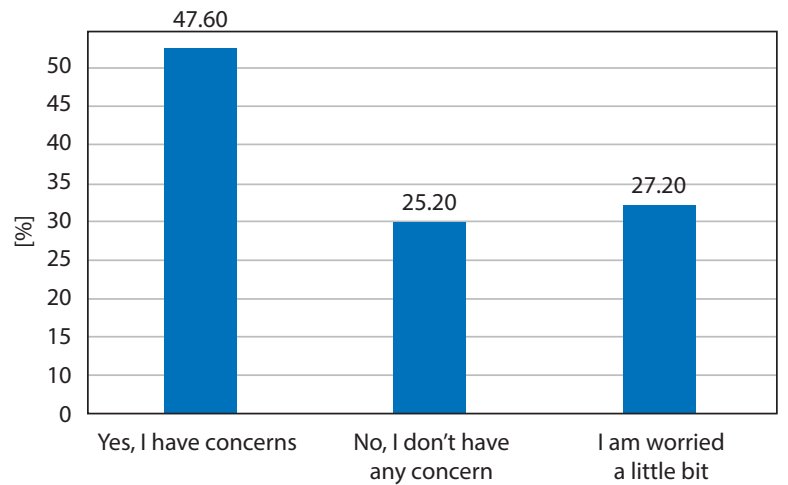

FIGURE 3. Concerns of academicians about their professions

ticipants' health was affected by a chronic disease. Moreover, $36.9 \%$ of partakers reported smoking.
As seen in Figure 1, the academicians reported obtaining information about COVID-19 from websites and/ or social media accounts of institutions, such as the Ministry of Health, WHO, professional organizations (88.3\%), medical books, medical journals, articles (54.4\%), and personal websites/social media accounts of physicians (52.4\%), followed by TV, communication groups (e.g., WhatsApp), and events, such as seminar, convention, or meetings held by organizations.

Opinions of the participants about their health regarding the coronavirus pandemic are presented in Figure 2A, and their concerns about transmitting the disease to their relatives are shown in Figure 2B. From the results, it can be seen that $4.9 \%$ of the participants had no concern, whereas $69.9 \%$ of them reported having concerns about their own health regarding the pandemic. Moreover, the percentage of academicians who were concerned about transmitting this virus to their families was over $98 \%$. 


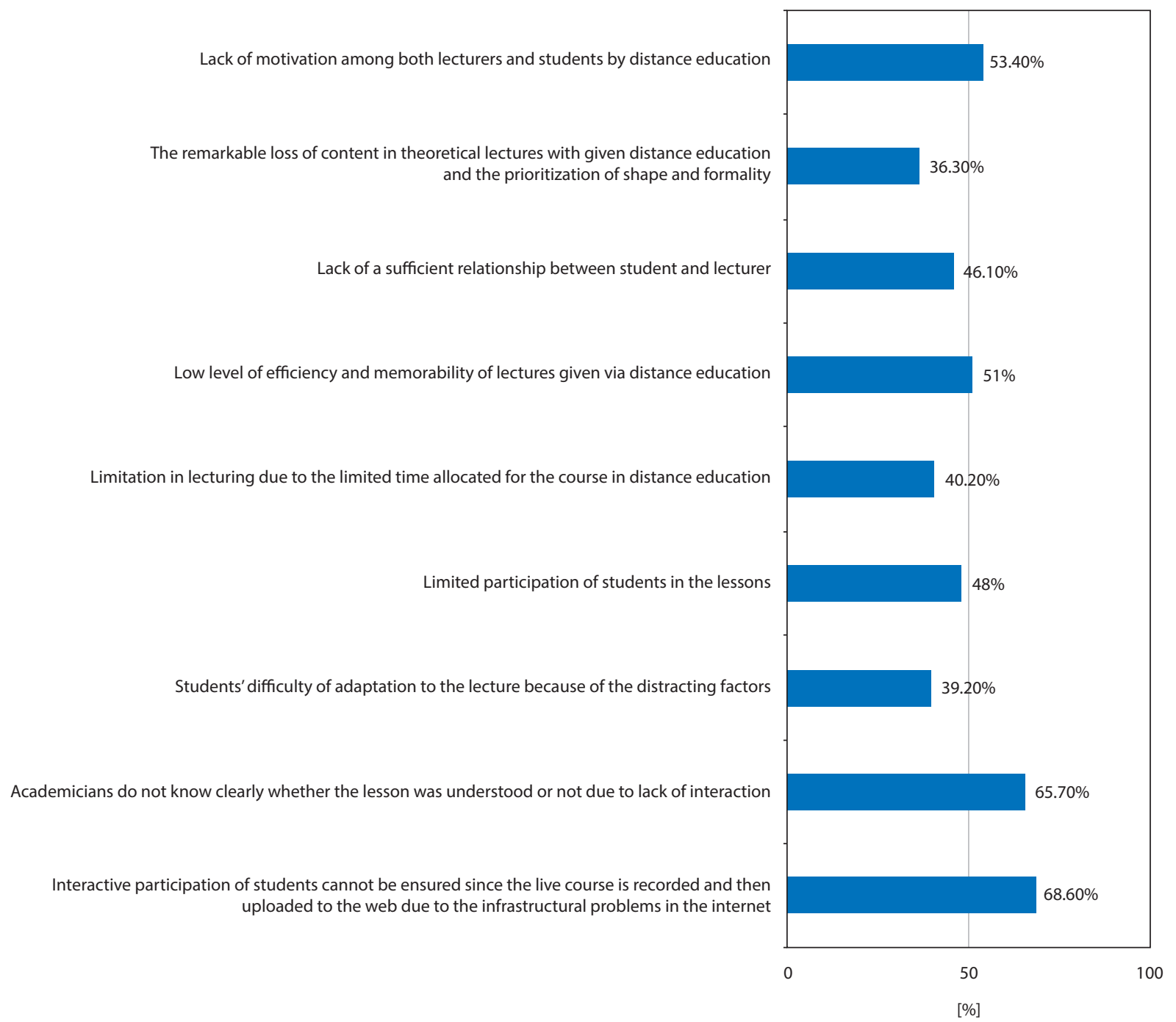

FIGURE 4. Academicians' opinions about the theoretical part of distance education

$84.3 \%$ of the participants reported that healthcare personnel should be tested regularly, even if they exhibit none of the COVID-19 symptoms, whereas $15.7 \%$ chose the answer "no" for this item. The healthcare personnel thinking that they should be tested regularly reported different ideas about the interval of the COVID-19 diagnostic test. Forty participants recommended that the test should be performed once every 14 days, whereas 30 participants suggested that the test should be repeated once every week, and 14 participants proposed once a month.

For a question about the future of their profession, $25.2 \%$ of the academicians working in medical sciences did not worried, whereas $74.8 \%$ reported concerns (Figure 3 ).

The participants were asked about their concerns about the theoretical part of distance education during the COVID-19 pandemic, and $68.6 \%$ of them reported that an interactive participation of students cannot be ensured since a live course was recorded and then uploaded to the web due to the infrastructural problems of Internet. $65.7 \%$ of the participants stated that they did not know clearly whether the lesson was under- stood or not. Other answers included lack of motivation among both lecturers and students by distance education (53.9\%), low level of efficiency and memorability of lectures given via distance education (51\%), limited participation of students in the lessons (48\%), lack of sufficient relationship between student and lecturer (46.1\%), limitation in lecturing due to limited time allocated for the course during distance education (40.2\%), students' difficulty of adaptation to the lecture because of distracting factors (39.2\%), remarkable loss of content in theoretical lectures during distance education, and prioritization of shape and formality (36.3\%) (Figure 4).

For a question about the effects of distance education system on clinical practices during the COVID-19 pandemic, $88.2 \%$ of the participants emphasized that the distance education would weaken professional practical skills because of the lack of practice, followed by limitation of students' ability to show their skills during distance education (68.6\%), decline in students' sense of belonging to their profession/ faculty (51\%), no sufficient relationship between students and faculty mem- 
Limitation of students' ability to show their skills due to distance education

Decline in students' sense of belonging to their profession/faculty

Loss of motivation due to the lack of compulsory attendance

Lack of sufficient relationship between students and faculty members

Distance education would weaken the professional practical skills because of the lack of practice

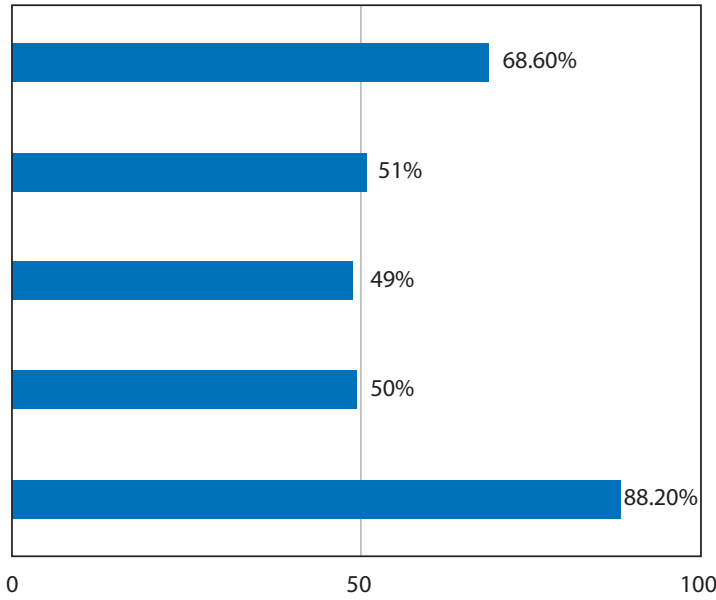

[\%]

FIGURE 5. Academicians' concerns about the effects of distance education system on the clinical practices during the COVID-19 pandemic

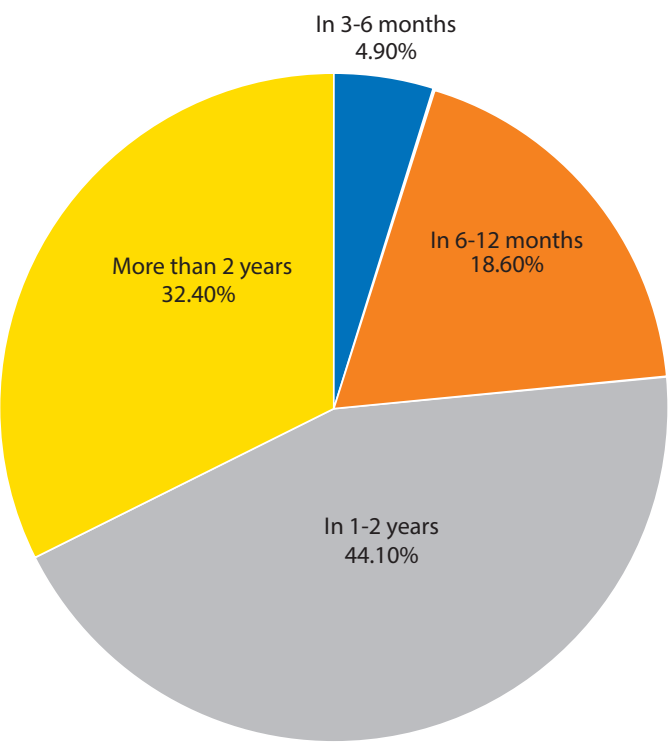

FIGURE 6. Academicians'opinions about when the practicability of clinical procedures will return to normal

bers (50\%), and loss of motivation due to lack of compulsory attendance (49\%) (Figure 5).

$58.8 \%$ of the participants declared permanent changes in their profession due to the COVID-19 pandemic, and $41.2 \%$ of them stated "no change". Among the academicians emphasizing permanent changes, $78.8 \%$ recommended the modification of clinical designs, considering possible pandemics in the future, and 59.1\% highlighted the transformation of face-to-face education, followed by changing internship programs of the students (45.5\%), requesting HES code before initiating treatment of patient $(37.9 \%)$, and re-evaluation of barrage of internship (25.8\%).

As seen in Figure 6, the opinions of academicians about the feasibility of clinical procedures interrupted due to the pandemic and when they will return to their previous forms vary. Some of the participants (44.1\%) noticed that this period would last for $1-2$ years, $32.4 \%$ declared for longer than 2 years, and $18.6 \%$ stated between 6-12 months. The first option "in 3-6 months" was chosen only by $4.9 \%$ of the academicians.

For a question "What their faculties /institutions should do in order to manage the current pandemic?", the most frequently given answers were hygiene measures $(76.7 \%)$, measures about the personnel (70.9\%), reducing the number of patients given healthcare (68\%), and patient information activities (61.2\%). Other answers included by ceasing providing healthcare (47.6\%), following the measures taken by the Ministry of Health (46.6\%), and digitalization in education (Figure 7).

\section{DISCUSSION}

As in many other fields, the economic, social, and psychological effects of the COVID-19 pandemic caused significant changes in healthcare system. With this survey conducted on healthcare-related academicians, while collecting data about the measures and approaches initiated specifically for the pandemic period, but influencing our professional habits even after the pandemic, it was aimed to evaluate the effects of COVID-19 on healthcare sector from an academicians' perspective.

Although studies on developing a vaccine and treatment are continuing at the moment, how this process will advance is not clearly known. The current literature reported that the pandemic will end either with a vaccine or via herd immunity when majority of the society will develop immunity [16]. It suggests that this pandemic will be influencing our lives for a long period of time. The risk of infection and increased workload compelling 


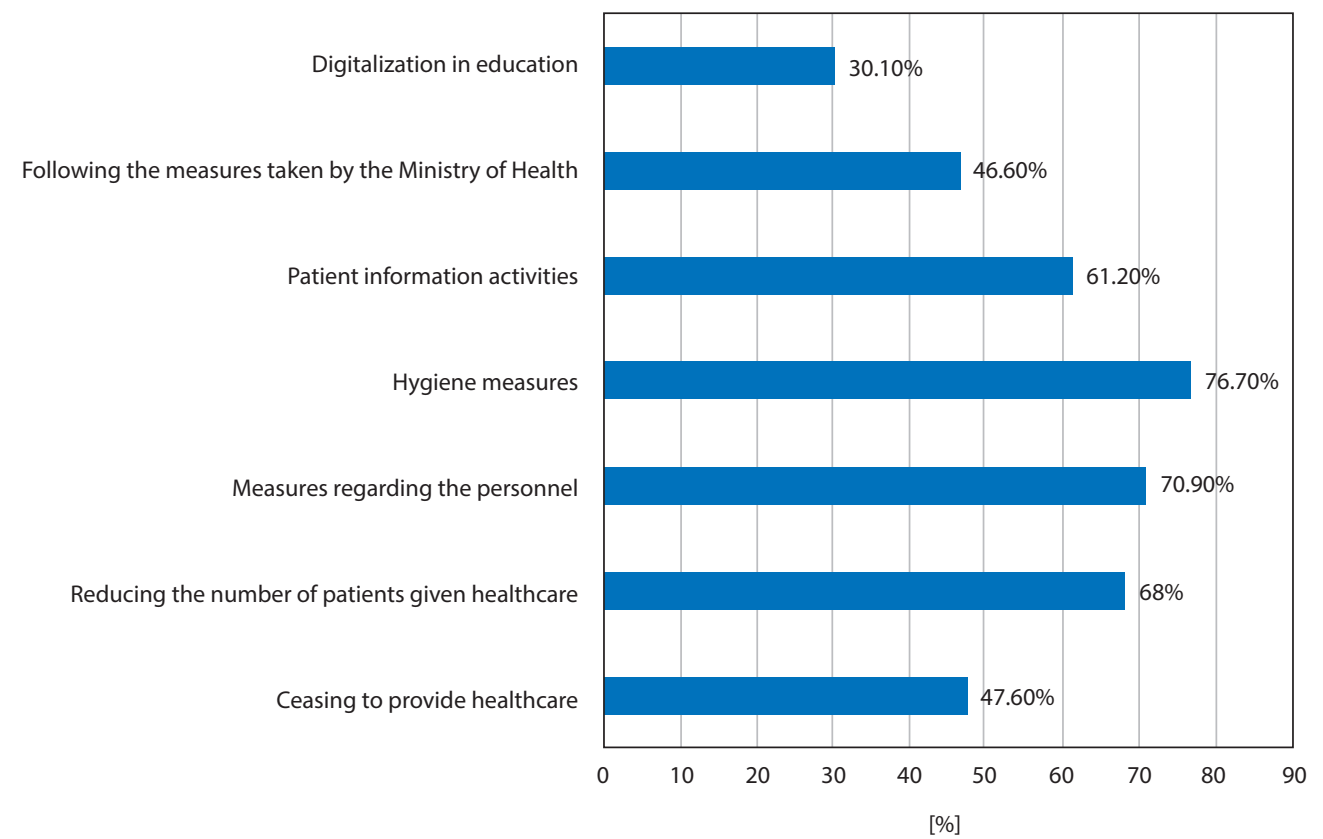

FIGURE 7. Academicians' opinions about what their faculties/institutions should do in order to manage the current pandemic

the capacity of the healthcare system, negatively affected the healthcare professionally. Healthcare professionals are anxious about transmitting the risk of infection (which they accept as a part of their profession) to their family members, and this situation creates psychological stress $[17,18]$. In parallel with the results of the present survey, it is recommended to prevent increasing the number of cases among healthcare personnel, who are the main component supporting our healthcare system in this pandemic, and to perform regular tests and early diagnosis among healthcare personnel to avoid potential interruptions in healthcare services [19].

Examining details of the COVID-19 pandemic's effect on the healthcare sector, it can be stated that not only the service-providing aspect, but also the educational aspect of process is negatively affected. In our country, the Council of Higher Education (YÖK) declared a 3-week suspension period for universities on $16^{\text {th }}$ March 2020 [20]; then, universities were informed that no formal education would be performed during the spring semester of 2019-2020 educational year, and they should initiate a distance education [21]. In Turkey and the rest of the world, an educational model consolidating theoretical knowledge with preclinical and clinical practices is implemented in professions associated with medical sciences. The students having education in these fields constitute a group, where the effect of the pandemic is realized at most, because their applied courses are given in hospitals. In particular, dentistry education differs from all other medical science education because this education has been an applied education throughout the history [22]. Since social distance restrictions are exceeded due to a high number of students in our country, theoretical parts of lectures are taught in distance education, but internship/ practical trainings are postponed for an unknown period. Both academicians and students tried to adapt themselves to distance education, which is not very common in medical sciences. When the academicians were asked about their concerns about the theoretical part of distance education, they answered that students could not participate interactively in the lessons because of the fact that the lesson was recorded and loaded into the system instead of the live lesson due to internet connection problems. However, in order to improve distance learning outcomes equivalent to face-to-face learning experiences, universities should support their students and faculty members by establishing a strong distance education infrastructure [23]. During the period of pandemic, the interaction with students is either synchronous [24], asynchronous [25], or both synchronous and asynchronous. When asynchronous presentation is chosen, the interaction decreases, and the students have problems with understanding the content due to reasons, such as lack of chance to ask a question and receive an answer, which demotivates the students. This is another issue worrying the academicians. In the synchronous model, however, the students can ask questions about the points they did not understand and, thanks to documents uploaded to the system, the students also have a chance of studying whenever and wherever they want. Another point worrying the academicians in this process was the decrease in effectiveness and memorability of lectures given in the distance education system. It was reported that the learning processes occur through 
social group interactions even in web-based education models [26], and high level of interaction between students increases the learning success and retention rates [27]. As implemented in our faculty, it has been shown that when the students were offered the combination of synchronous and asynchronous interaction, the efficiency increased [28]. While synchronous presentation allows structuring the knowledge together with immediate interaction, asynchronous model enables students to think about the subject and to do a research using different sources. Furthermore, there were also several concerns about the theoretical education, such as limited participation (since students think that they could listen to lecture later) and limited interaction between student and academician, difficulty to focus on the lecture due to distractors around the student, limitation in lecturing because of the limited time, and the importance given to formality rather than content.

In professions associated with medical sciences, even though the theoretical part of education can be conducted through the Internet, the problems remain in internship/ practical trainings. It was reported that practicing after listening to the lecture further increases the professional skills of students having education in applied sciences [29]. When asked about their concerns about the effects of distance education on practical applications, the academicians responded that significant lack of practice would weaken the professional practice skills and students would be limited to show their professional skills. It is through their education and experiences gained, students prepare themself for the chosen profession, which make them a part of the healthcare system. In the pandemic process, another point worrying the academicians was the decrease in students' sense of belonging to their profession/ faculty.

In case of the COVID-19 pandemic, with its possible long-lasting effects, it is inevitable that the healthcare system and related professions will be affected. Institutions offering medical education should review their protocols and establish a detailed emergency plan for possible future pandemics, prepare for such pandemics by modifying clinical designs (isolation of clinic where the risky procedures are conducted, preparation of negative-pressure treatment rooms, etc.), and minimize an interruption in education [30]. Universities should make radical reforms in education and be encouraged to include distance education methods in competency-based education systems as well as provide haptic technology to improve students' control [30].

In order to manage the current pandemic crisis, it is very important in the medical institutions to act in accordance with the recommendations of the Turkish Ministry of Health - Science Council, to follow the hygiene and distance rules, take measures for healthcare personnel, prolong the interval between appointments by decreasing the number of patients given healthcare, and appropriate inform the patients.
Nowadays, the effects of the COVID-19 pandemic have accelerated vaccine development efforts. The current situation in vaccine development studies is important because it provides a slight decrease in the concerns about the education and functioning of the healthcare faculties. Further studies are needed investigating the knowledge of healthcare professionals about vaccine studies and their approach to vaccination.

\section{CONCLUSIONS}

Various strategies should be developed in order to provide patients a high-quality service, manage the struggle effectively, and protect the healthcare personnel from the pandemic in any public health emergencies. The institutions providing medical education should review their policies and protocols, and should establish a detailed emergency plan for future pandemics. In these difficult times, it is our responsibility to follow the recommended procedures, implementing them into practice accurately, and continuously monitor the process. In this pandemic process with rapidly changing dynamics, it is very important to inform the healthcare personnel about the course of proceeding and treatment methods, which are suitable for the conditions of a particular country, so, the process can be accurately managed.

\section{CONFLICT OF INTEREST}

The authors declare no potential conflicts of interest with respect to the research, authorship, and/or publication of this article.

\section{References}

1. Lu R, Zhao X, Li J, et al. Genomic characterisation and epidemiology of 2019 novel coronavirus: implications for virus origins and receptor binding. Lancet 2020; 395: 565-574.

2. Cascella M, Rajnik M, Cuomo A, Dulebohn SC, Di Napoli R. Features, evaluation and treatment coronavirus (COVID-19). In: Statpearls [internet]. StatPearls Publishing; 2020.

3. Gorbalenya AE, Baker SC, Baric R, et al. Severe acute respiratory syndrome-related coronavirus: the species and its viruses a statement of the Coronavirus Study Group. Nat Microbiol 2020; 5: 536-544.

4. World Health Organization. Coronavirus disease 2019 (COVID-19). Situation report-51. https://www.who.int/docs/default-source/ coronaviruse/situation-reports/20200311-sitrep-51-covid-19.pdf ?sfvrsn=1ba62e57_10 (Accessed: 27.11.2020).

5. Huang C, Wang Y, Li X, et al. Clinical features of patients infected with 2019 novel coronavirus in Wuhan, China. Lancet 2020; 395: 497-506.

6. Chen N, Zhou M, Dong X, et al. Epidemiological and clinical characteristics of 99 cases of 2019 novel coronavirus pneumonia in Wuhan, China: a descriptive study. Lancet 2020; 395: 507-513.

7. Guan WJ, Ni ZY, Hu Y, et al. Clinical characteristics of 2019 novel coronavirus infection in China. N Engl J Med 2020; 382: 1708-1720.

8. Wang D, Hu B, Hu C, et al. Clinical characteristics of 138 hospitalized patients with 2019 novel coronavirus-infected pneumonia in Wuhan, China. JAMA 2020; 323: 1061-1069. 
9. Kui L, Fang YY, Deng Y, et al. Clinical characteristics of novel coronavirus cases in tertiary hospitals in Hubei Province. Chin Med J 2020; 133: 1025-1031.

10. WorldHealthOrganization.ClinicalmanagementofCOVID-19.Interim guidance; 27 May 2020. https://www.who.int/publications/i/ item/clinical-management-of-covid-19 (Accessed: 27.11.2020). Lu CW, Liu XF, Jia ZF. 2019-nCoV transmission through the ocular surface must not be ignored. Lancet 2020; 395: e39.

11. Wax RS, Christian MD. Practical recommendations for critical care and anesthesiology teams caring for novel coronavirus (2019-nCoV) patients. Can J Anaesth 2020; 67: 568-576.

12. Meng L, Hua F, Bian Z. Coronavirus disease 2019 (COVID-19): emerging and future challenges for dental and oral medicine. J Dent Res 2020; 99: 481-487.

13. Rothe C, Schunk M, Sothmann P, et al. Trans-mission of 2019$\mathrm{nCoV}$ infection from an asymptomatic contact in Germany. N Engl J Med 2020; 382: 970-971.

14. U.S. Department of Labor, Occupational Safety and Health Administration. Guidance on preparing workplaces for COVID-19. OSHA 3990-03 2020. https://www.osha.gov/Publications/OSHA3990. pdf (Accessed: 27.11.2020).

15. Yatğın SK, Tonguç MÖ. Dentistry in the COVID-19 pandemic SDU J H Sci 2020; 11: 376-382. DOI: 10.22312/sdusbed.791701 [In Turkish].

16. Adams JG, Walls RM. Supporting the health care workforce during the COVID-19 global epidemic. JAMA 2020; 323: 1439-1440.

17. Rana W, Mukhtar S, Mukhtar S. Mental health of medical workers in Pakistan during the pandemic COVID-19 outbreak. Asian J Psychiatry 2020; 51: 102080.

18. Dikmen AU, Kına MH, Özkan S, İlhan MN. Epidemiology of COVID-19: what we learn from pandemic. J Biotechnol Strateg Health Res 2020; 4: 29-36 [In Turkish].

19. The Council of Higher Education (YÖK) Coronavirus (COVID-19) information note:1(03.13.20) https://www.yok.gov. tr/Sayfalar/Haberler/2020/coronavirus_bilgilendirme_1.aspx (Accessed: 27.11. 2020).

20. The CouncilofHigherEducation(YÖK) Pressbriefing (03.26.2020) https://www.yok.gov.tr/Sayfalar/Haberler/2020/YKS\%20 Ertelenmesi\%20Bas\%C4\%B1n\%20A\%C3\%A7\%C4\%B1klamas\% C4\%B1.aspx (Accessed: 27.11.2020).

21. Sweet J, Wilson J, Pugsley L. Chairside teaching and the perceptions of dental teachers in the UK. Br Dent J 2008; 205: 565-569.

22. Durak G, Çankaya S, İzmirli S. Examining the Turkish universities' distance education systems during the COVID-19 pandemic. NFE-EJSME 2020; 14: 787-809 [In Turkish].

23. Henriksen D, Creely E, Henderson M. Folk pedagogies for teacher transitions: approaches to synchronous online learning in the wake of COVID-19. JTATE 2020; 28: 201-209.

24. Lowenthal P, Borup J, West R, Archambault L. Thinking beyond zoom: using asynchronous video to maintain connection and engagement during the COVID-19 pandemic. JTATE 2020; 28: 383-391.

25. Clark C, Strudler N, Grove, K. Comparing asynchronous and synchronous video vs. text based discussions in an online teacher education course. Online Learn J 2015; 19: 48-69.

26. Lai $\mathrm{CH}$, Lin HW, Lin RM, Tho PD. Effect of peer interaction among online learning community on learning engagement and achievement. IJDET 2019; 17: 66-77.

27. Moallem M, Pastore R, Martin M. Interaction in online learning: A comparative study on the impact of communication tools on student learning, motivation, self-regulation, and satisfaction. In Society for Information Technology \& Teacher Education International Conference. Association for the Advancement of Computing in Education (AACE) 2013; 2286-2306. http://www.editlib. org $/ \mathrm{p} / 48448 /$.

28. Keskin M, Özer Kaya D. Evaluation of students' feedbacks on web-based distance education in the COVID-19 process. İzmir Katip Çelebi Univ Fac Health Sci J 2020; 5: 59-67 [In Turkish].

29. Iyer P, Aziz K, Ojcius DM. Impact of COVID-19 on dental education in the United States. J Dent Educ 2020; 84: 718-722 